\title{
Exploring critical attributes during air traffic congestion with a fuzzy DEMATEL-ANP technique: a case study in Ninoy Aquino International Airport
}

\author{
Miriam F. Bongo ${ }^{1} \cdot$ Lanndon A. Ocampo $^{2}$ (D)
}

Received: 3 July 2017/Revised: 31 October 2017/Accepted: 2 November 2017/Published online: 21 November 2017

(c) The Author(s) 2017. This article is an open access publication

\begin{abstract}
The constant growth of air travel in the Philippines has brought about significant consequences to air traffic congestion. Given limited resources, major airports seek to address this issue while considering various attributes generally affecting air transportation. This paper adopts fuzzy decision-making trial and evaluation laboratory-analytic network process (DEMATEL-ANP) to identify the most critical attributes in the commercial aviation industry. A case study participated by key experts of Ninoy Aquino International Airport was conducted to illustrate the proposed approach. The fuzzy DEMATELANP model performed satisfactorily as it was able to extract the global priority vectors of attributes under a fuzzy environment. The results showed that aviation safety is most prioritized, as can also be seen from the significant influence it brings on other attributes. Following next to safety in terms of priority are attributes that address the general air transportation system such as economic value, environmental value, social value, equitable treatment of competing airline, customer goodwill, and utilization of runway and terminal. Then, attributes relating to passenger cost, fuel cost, extra crew cost, landing/take-off fee, and cost of using flight routes are of last priority. Given the
\end{abstract}

An earlier version of this paper is presented at the 3rd International Conference on Industrial Engineering, Management Science and Applications, Jeju Island, South Korea on May 2016.

Lanndon A. Ocampo

lanndonocampo@gmail.com

1 Department of Mechanical and Manufacturing Engineering, University of San Carlos, Cebu City 6000, Philippines

2 Department of Industrial Engineering, Cebu Technological University, Corner M.J. Cuenco Ave. \& R. Palma St., Cebu City 6000, Philippines order of priorities and criticality of each attribute, shortterm and long-term policies can be framed accordingly to propose air traffic flow management actions that can best address the issue on congestion.

Keywords Air traffic congestion · ANP · Fuzzy DEMATEL · MCDM

\section{Introduction}

One of the direct effects of air traffic congestion is flight delays [1]. With such occurrences, airlines' on-time schedule reliability, airports' operational reputation, and the quality of customer service experienced by air passengers are compromised. As a consequence, not only are the order and flow of scheduled flights seriously disrupted and at stake, but also the aviation safety (i.e., a state in which the risk of harm to persons or property damage is reduced to and maintained at or below an acceptable level through a continuing process of hazard identification and risk management [2]) will be influenced. In the same manner, both airports and airlines management are faced with huge losses and low credit [3]. In 2015, the Air Traffic Services (ATS) of the Civil Aviation Authority of the Philippines (CAAP) has recorded that $14 \%$ of flights on an average daily basis are delayed. This statistical data, although relatively small in figure, further express that the issue of flight delays is a serious threat to the stakeholders of the commercial aviation industry consisting of the airline industry, airport management, and air traffic service providers, as its effects accumulate from one flight leg to another. In order to reduce, if not eradicate, flight delays, there is a need to investigate the deep cause of such phenomenon. According to ATS-CAAP, the leading cause of 
delays in the Philippines is air traffic congestion, accounting for $40 \%$ of the total annual delays. With air traffic congestion recognized as the root cause of delays, various air traffic flow management (ATFM) actions are believed to respond to the issue and are thereby implemented in the Philippine setting. These ATFM actions are, but not limited to, ground holding, airborne holding, rerouting, and speed controlling [4].

To address the issue of air traffic congestion caused by either airport congestion or airspace congestion [5, 6], strategies are framed according to phases of planning. These are dependent on three specific time horizons: (1) long-term approaches involving strategic planning, (2) medium-term approaches involving pre-tactical planning, and (3) short-term approaches involving tactical planning. Strategic planning is carried out more than one day before the operation to ensure that limited airport slots are efficiently utilized and demand-capacity issues are addressed. For pre-tactical planning, the action is taken a day prior to the day of operation. It covers analyses and decisions concerning the best way to manage the available capacity resources. When the action is applied on the day of operation, it is referred to as tactical planning. Actual traffic and capacity are based upon implementing ground delays by modifying the expected departure clearance time. For instance, Sölveling [7] proposed a long-term approach of addressing capacity scarcity by modifying an airport's configuration and increasing its runway efficiency. Although this approach may potentially increase capacity, it is rendered highly unlikely due to high investments, environmental impact, lengthy approval process, and political feasibility [8]. In addition to airport configuration modification, Janic [9] presented other available options for matching airport system capacity to demand such as managing air transport demand, switching part of the current and prospective demand to other transport modes, and combinations of the previous options.

Outstanding studies in current literature engaged in optimization models and learning algorithms are framed within the context of implementing directly one or a combination of ATFM actions bounded by a predetermined attribute (e.g., safety or timeliness). However, such models are not inclusive and fail to logically justify the viability of an ATFM action implemented given that only a single attribute is taken into account when, in practice, a number of attributes are considered by several decisionmakers in the air transportation system.

In the domain literature, the use of multi-criteria decision-making (MCDM) approaches such as decision-making trial and evaluation laboratory (DEMATEL) and analytical network process (ANP), has become a growing platform to address various air transportation management issues. Among others are (1) selection of preferred alternative/candidate airport for 'building a new runway' [9], (2) evaluation of perceived airport quality and its impact on profitability [10], (3) improvement of airline service quality [11], (4) evaluation of airports service quality [12], (5) assessment for potential multi-airport systems [13], and (6) analysis on the managerial efficiency of airports in Brazil [14]. Furthermore, results from MCDM approaches are proven promising and significant in addressing issues in air transportation system.

While addressing decision management problems concerned with air transportation system using MCDM approach is proven highly viable by prior domain studies, to the authors' knowledge, no attempt has yet investigated the inherent relationships among attributes and their corresponding characteristics. This is a significant step to be undertaken since the very nature of imposing a policy (i.e., implementing an ATFM action) during such conditions relies greatly on how an attribute is given due consideration by decision-makers. That is, a selected ATFM action may vary depending on the established interrelations of critical attributes. Further, when the interrelations among attributes are identified, decision-makers can make use of this information in constructing a general framework that will address the current issue at hand and confront other possible issues in the future which also consider the same set of attributes and same decision problem in different conditions. It is also imperative to note that both airport and airspace resources can be better allocated when policies made are sensitive to the characteristics of attributes considered. By having such policies set, the management of available capacities in an airport and airspace in terms of strategic and tactical planning can well follow a more organized guideline.

There is, however, a recent work done by Bongo and Ocampo [15] which particularly uses fuzzy MCDM in addressing airport congestion. The study focuses on the selection of ATFM action when airport congestion occurs. Although their study was able to extract the inherent characteristics of multiple attributes involved in making air traffic decisions during a specific scenario of congestion, it failed to generalize the case of congestion. By means of generalizing the case, other possibilities of air traffic congestion, such as airspace congestion which is also believed as a dominant issue together with airport congestion [16], can be further taken into account in selecting an ATFM action for implementation. When both the airport and the airspace congestion are considered, decision-makers can direct the regulations relating to policy-making during air traffic congestion into a more holistic view.

The aim of this paper is to create a multi-attribute decision support system to guide decision-makers (i.e., airline industry, airport management, and ATS providers) by taking into account various critical attributes upon 
which the choice of an implemented ATFM action must be based. Based on the concepts of fuzzy set theory, DEMATEL, and ANP, an integrated MCDM approach is applied in order to achieve the objective of the paper. The use of MCDM methods such as DEMATEL and ANP is deemed necessary in order to map out the complex relationships among attributes and to analyze their interactions. DEMATEL is believed to be an effective procedure for analyzing structure and relationships among attributes [17]. Attributes with higher impact on another are given higher priority, and attributes with lower impact are considered to have lower priority. Once the relationship among attributes is known in terms of its impact, ANP can be integrated to determine the weights of each attribute. Saaty [18] proposed ANP to deal with the dependence and the feedback decision-making. This method is widely applied to various decision management problems. Additionally, in the application of fuzzy set theory, decision-makers are provided with more ease in eliciting judgment using natural linguistic variables, and such variables can be logically represented by fuzzy numbers. According to Kuo [11], the fuzzy set theory can handle the uncertainty of human decision-making process and it also serves as an appropriate tool to evaluate qualitative attributes such as safety and customer goodwill. Therefore, the use of fuzzy numbers in the context of this paper is deemed suitable.

Given the need to investigate the inherent characteristics of attributes involved in the decision-making process to mitigate air traffic congestion, an integrated MCDM method is used in this paper. In particular, the major contribution of this paper lies in its focus on a general case of congestion which considers the likelihood that both airport and airspace congestion may have caused the issue. The extracted relations among attributes can further lead decision-makers in framing air transport policies that should be implemented in various cases of congestion. A case study in Ninoy Aquino International Airport (NAIA) was conducted in order to demonstrate the proposed approach.

\section{Case study: Ninoy Aquino International Airport (NAIA)}

The Ninoy Aquino International Airport (NAIA), located along the border between Pasay City and Parañaque City in Manila, serves as the Philippines' major gateway to both international and domestic air travel. Currently, it houses four terminal facilities to accommodate the continuing growth of air passengers. In 2014, NAIA has catered for more than 34,000,000 air passengers delivered by over 200,000 flights. Due to the fact that NAIA accommodates various types of aircraft ranging from long-haul international jets to domestic planes and that it has two runways which intersect at one point, the airport becomes more congested and air traffic control becomes difficult as well.

The airport management, handled by Manila International Airport Authority (MIAA) and the government, has long recognized that air traffic congestion is evident in NAIA. The construction of NAIA Terminal 2, Terminal 3, and Terminal 4 is held under the belief that it is going to address this issue. Efforts to decongest NAIA by improving terminal facilities and constructing another runway are continued to strive. When implemented, the number of planes taking off and landing is expected to increase. This scenario benefits the airlines operating domestic and international travels via NAIA.

However, as airlines practice competitive scheduling as a means of retaining market shares, the volatility of a flight's travel time is significantly affected. With the utilization of smaller aircraft with increased frequency, air traffic congestion becomes more apparent. Nevertheless, it is the airline industry's goal to deliver flights on time by dictating aircraft to follow a scheduled departure from origin airport. Any form of deviation from the predetermined schedule (i.e., excessive ground holding, late departure, and arrival, or delays during the en-route phase and descent phase) can be charged to them accordingly.

Another stakeholder involved in the commercial aviation industry is the ATS providers which function directly under the Civil Aviation Authority of the Philippines (DOTC-CAAP). There are three air traffic services composed of area control center (ACC), terminal radar control (TRACON), and aerodrome control tower (ADCT) that provide flight information services, alert service, air traffic advisory services, and air traffic control service. A recent policy by CAAP in the form of a Memorandum Circular No. 15-12 is issued to address the air traffic congestion at NAIA. It mandates airlines to communicate with the aerodrome control tower or flight service station prior to departure. A ground delay program for flights arriving at NAIA is employed where aircraft shall be allowed to depart only upon the authority of an estimated departure clearance time.

In the general air transportation system, a wide range of attributes presents a major interest to the stakeholders in terms of making decisions during air traffic congestion. In the case of NAIA, relevant attributes $\left(C_{j}, j=1,2, \ldots, 12\right)$ are summarized as in Table 1.

\section{A step-by-step methodology of the hybrid approach}

The initial step involves the participation of three decisionmakers (i.e., an airport manager, airlines station manager, and ATFM officer) where an evaluation in terms of 
Table 1 List of attributes considered during air traffic congestion [15]

\begin{tabular}{|c|c|}
\hline Attribute & Brief description \\
\hline Cost of using flight routes $\left(C_{1}\right)$ & $\begin{array}{l}\text { An original route is indicated in the official airline guide which is submitted to the ATS prior to an } \\
\text { aircraft's flight. The use of an alternative flight route will incur additional costs particularly when the } \\
\text { alternate preferred route is costlier than the previous original route }\end{array}$ \\
\hline Landing/take-off fee $\left(C_{2}\right)[19]$ & $\begin{array}{l}\text { Under a system of congestion charges, aircraft will be assessed two separate fees. The first fee is for the } \\
\text { congestion caused when they land and a second fee covers the congestion caused when they take off. } \\
\text { In most traditional airport pricing systems, both fees can be assessed as a single congestion fee that } \\
\text { covers both landing and taking off. The measure of congestion fees is that of the marginal additional } \\
\text { congestion externality enforced by other flights }\end{array}$ \\
\hline Fuel cost $\left(C_{3}\right)[6]$ & $\begin{array}{l}\text { This attribute is characterized by an excess consumption of fuel in cases of deviation from original flight } \\
\text { plan set caused by rerouting and speed control }\end{array}$ \\
\hline Extra crew cost $\left(C_{4}\right)[6]$ & $\begin{array}{l}\text { Airlines crew are paid on an hourly basis, and an excess of rendered service hours would result in } \\
\text { additional extra crew costs }\end{array}$ \\
\hline Passenger cost $\left(C_{5}\right)[6]$ & $\begin{array}{l}\text { This attribute includes costs related to instances of missed passenger connections, foregone revenues, and } \\
\text { per diem charges for food and lodging for passengers with delayed and/or canceled flights }\end{array}$ \\
\hline Customer goodwill $\left(C_{6}\right)[6]$ & $\begin{array}{l}\text { The attractiveness of an airline, especially to the high-yield business passengers, is dependent on service } \\
\text { reliability which is also associated with an airline's on-time performance }\end{array}$ \\
\hline Safety $\left(C_{7}\right)[20]$ & $\begin{array}{l}\text { Some ATFM actions are perceived as safer to execute over the others. One clear illustration for this } \\
\text { notion is the comparison between ground holding and airborne holding in terms of safety. In cases of } \\
\text { reduced visibility caused by poor weather, arriving aircraft are obliged to be separated by a wider than } \\
\text { usual margin to ensure safety [6] }\end{array}$ \\
\hline $\begin{array}{l}\text { Equitable treatment of competing } \\
\text { airline }\left(C_{8}\right)[20]\end{array}$ & $\begin{array}{l}\text { While airline management observes that NAIA uses the information they provided to allow a much } \\
\text { greater benefit to their competition, the equality and fairness among competing airline is considered an } \\
\text { important attribute. This is represented by the principle of ration-by-schedule which is based on the } \\
\text { agreed allocation procedures among stakeholders }\end{array}$ \\
\hline $\begin{array}{l}\text { Utilization of runway and terminal } \\
\qquad\left(C_{9}\right)[21]\end{array}$ & $\begin{array}{l}\text { For airport management, the utilization of the runway and terminals is considered to have a significant } \\
\text { impact in achieving its goal of being a reliable, efficient air transportation system. By maximized use } \\
\text { of runway and terminals, substantial benefits to society are attained considering that distant } \\
\text { communities in broader national and international economies are connected [8] }\end{array}$ \\
\hline Environmental value $\left(C_{10}\right)[22]$ & $\begin{array}{l}\text { This attribute takes into consideration the emphasis on the environmental dimension that is affected by } \\
\text { the air traffic. These dimensions include noise, air quality, and climate change. It is directly presented } \\
\text { by Babic et al. [22] that improvements in air traffic management are the most important element in } \\
\text { meeting the goal of reducing } \mathrm{CO}_{2} \text { emissions by an average of } 10 \% \text { per flight }\end{array}$ \\
\hline Economic value $\left(C_{11}\right)[13]$ & $\begin{array}{l}\text { As air travel demand increases, an economy from which an airport is situated also grows proportionally. } \\
\text { Also, airports significantly influence the economy and economic growth. In addition to its influence, } \\
\text { airport's infrastructure characteristics or economic activities are also able to play a crucial role in } \\
\text { increasing territorial competitiveness. Therefore, it is a vital role of the air transportation system to } \\
\text { provide constant solutions in addressing the growing air travel demand }\end{array}$ \\
\hline Social value $\left(C_{12}\right)[13]$ & $\begin{array}{l}\text { The social value of an airport can be generated based on its capability of having the infrastructure built } \\
\text { for the development of the regional economy [23]. One general infrastructure in an airport is the } \\
\text { runway system, which supports the increased demand for air travel. With increasing air travel demand, } \\
\text { more congestion at airports and more delays for air travelers are created, resulting in ever greater social } \\
\text { costs on pricing congestion and even investments [24] }\end{array}$ \\
\hline
\end{tabular}

influence among attributes is made using a survey questionnaire. The decision-makers' expertise is considered essential in eliciting judgment in order to mitigate air traffic congestion. A set of linguistic expressions used in evaluating the attributes along with its corresponding triangular fuzzy number is shown in Table 2.

The hybrid fuzzy MCDM approach refers to the synergy of three methodologies (i.e., fuzzy set theory, DEMATEL, and ANP) to obtain a better illustration of how air traffic congestion may be addressed using such a hybrid approach. While the three methodologies provide ease of decision- making independently in terms of handling vagueness of judgment, analyzing structures and interactions among attributes, and dealing with the dependence and feedback among attributes, respectively, when applied together as in a hybrid manner, this provides a more comprehensive representation of the decision problem. The fuzzy DEMATEL and ANP methods are described below:

Step 1 Aggregate linguistic values from decision-makers' evaluation according to Tseng [26].

This step is done in order to get the aggregate fuzzy linguistic values of the evaluation among attributes. 
Table 2 Description of the linguistic expressions for evaluating the attributes

\begin{tabular}{lll}
\hline Linguistic expression & Description & Triangular fuzzy number \\
\hline No influence (NI) & Base attribute has no influence on another attribute & $(0.0,0.1,0.3)$ \\
Very low influence (VLI) & Base attribute has very low influence on another attribute & $(0.1,0.3,0.5)$ \\
Low influence (LI) & Base attribute has low influence on another attribute & $(0.3,0.5,0.7)$ \\
High influence (HI) & Base attribute has high influence on another attribute & $(0.5,0.7,0.9)$ \\
Very high influence (VHI) & Base attribute has very high influence on another attribute & $(0.7,0.9,1.0)$ \\
\hline
\end{tabular}

The triangular fuzzy numbers presented in this table per linguistic expression are adapted from that of early definitions of Wang and Chang [25], used by Chen [17], and recently referred to by Bongo and Ocampo [15]

Aggregation of decisions can be computed by means of synthetic value notation as in Eq. (1).

$\tilde{w}_{j}=\frac{1}{k} \tilde{w}_{j}^{1}+\tilde{w}_{j}^{2}+\tilde{w}_{j}^{3}+\cdots+\tilde{w}_{j}^{k}$,

where $\tilde{w}_{j}$ is the aggregated rating for the $j$ th attribute $\left(C_{j}\right)$, $\tilde{w}_{j}^{i}(i=1,2, \ldots, k)$ is the individual rating of the $k$ th decision-maker for the $j$ th attribute.

Step 2 Defuzzify corresponding linguistic values by means of signed distance method.

The results of the survey conducted initially involve triangular fuzzy set numbers. In order to allow direct comparison of fuzzy numbers, a defuzzification method is employed. For this paper, the signed distance method as expressed in Eq. (2) is used. This method is proven better than other defuzzification methods such as the centroid method based on the maximum membership grade principle which states that the triangle created by such fuzzy numbers may not necessarily be isosceles [27]. The crisp values of the results will then be used in the succeeding steps.

$d=\frac{a+2 b+c}{4}$,

where $d$ is the crisp value of fuzzy number $(a, b, c)$, i.e., $a$ for the lower limit, $b$ for the mean, and $c$ for the upper limit.

Step 3 Apply DEMATEL and ANP methods according to Tzeng et al. [28] by calculating the direct-influential matrix by scores first.

The relationship between each mutual influence is established according to the opinions of decision-makers using a linguistic scale rating previously presented in Table 2. The scores are represented by natural language, 'no influence' (NI), 'very low influence' (VLO), 'low influence' (LI), 'high influence' (HI), and 'very high influence' (VHI), accordingly. In this step, the decisionmakers are required to evaluate the direct influence exerted by one attribute on another. When attribute $i$ is believed to influence attribute $j$, we denote the influence by $g_{i j}$. Thus, a matrix $\boldsymbol{G}=\left[g_{i j}\right]_{n \times n}$ of direct relationships, called as the direct-influential matrix hereinafter, can be obtained as follows:

$$
\boldsymbol{G}=\left[\begin{array}{ccccc}
g_{11} & \cdots & g_{1 j} & \cdots & g_{1 n} \\
g_{21} & \cdots & g_{2 j} & \cdots & g_{2 n} \\
\vdots & & \vdots & & \vdots \\
g_{(i-1) 1} & \cdots & g_{(i-1) j} & \cdots & g_{(i-1) n} \\
g_{i 1} & \cdots & g_{i j} & \cdots & g_{i n} \\
g_{(i+1) 1} & \cdots & g_{(i+1) j} & \cdots & g_{(i+1) n} \\
\vdots & & \vdots & & \vdots \\
g_{(n-1) 1} & \cdots & g_{(n-1) j} & \cdots & g_{(n-1) n} \\
g_{n 1} & \cdots & g_{n j} & \cdots & g_{n n}
\end{array}\right] .
$$

Step 4 Normalize the direct-influential matrix $\boldsymbol{G}$.

To normalize the direct-influential matrix $\boldsymbol{G}$, Eq. (4) is used. The diagonal of the normalized direct-influential matrix $\boldsymbol{X}$ is zero, and the maximum sum of rows or columns is one.

$\boldsymbol{X}=\nu \boldsymbol{G}$,

where

$\boldsymbol{v}=\min _{i, j}\left\{\frac{1}{\max _{i} \sum_{j=1}^{n} g_{i j}}, \frac{1}{\max _{j} \sum_{i=1}^{n} g_{i j}}\right\}$,

$i, j \in\{1,2, \ldots, n\}$.

Step 5 Attain a total-influential matrix $\boldsymbol{T}$.

The total-influential matrix $\boldsymbol{T}$ can be calculated using Eq. (5), where $\boldsymbol{I}$ denotes the identity matrix and $\ell$ is degree of $\boldsymbol{X}$.

$$
\begin{aligned}
\boldsymbol{T} & =\boldsymbol{X}+\boldsymbol{X}^{2}+\boldsymbol{X}^{3}+\cdots+\boldsymbol{X}^{\ell} \\
& =\boldsymbol{X}\left(\boldsymbol{I}+\boldsymbol{X}+\boldsymbol{X}^{2}+\cdots+\boldsymbol{X}^{\ell-1}\right)(\boldsymbol{I}-\boldsymbol{X})(\boldsymbol{I}-\boldsymbol{X})^{-1} \\
& =\boldsymbol{X}\left(\boldsymbol{I}-\boldsymbol{X}^{\ell}\right)(\boldsymbol{I}-\boldsymbol{X})^{-1} \\
& =\boldsymbol{X}(\boldsymbol{I}-\boldsymbol{X})^{-1}, \text { when } \lim _{\ell \rightarrow \infty} \boldsymbol{X}^{\ell}=\mathbf{0}_{n \times n} .
\end{aligned}
$$

Note that $\boldsymbol{X}=\left[x_{i j}\right]_{n \times n}, \quad 0 \leq x_{i j}<1, \quad 0<\sum_{j=1}^{n} x_{i j} \leq 1$, and $0<\sum_{i=1}^{n} x_{i j} \leq 1$, and at least one row or column of the summation equals one; then, $\lim _{\ell \rightarrow \infty} \boldsymbol{X}^{\ell}=\mathbf{0}_{n \times n}$ can be guaranteed. 
Step 6 Analyze the results.

The row and column sums of matrix $\boldsymbol{T}$, as shown in Eq. (6), are expressed as vectors $\boldsymbol{r}$ and $\boldsymbol{s}$, respectively using Eqs. (7) and (8), where the superscript ' denotes the transpose of matrix components. Note that for this paper, matrix $\boldsymbol{T}$ also represents the unweighted supermatrix in the context of the ANP.

$\boldsymbol{T}=\left[t_{i j}\right]_{n \times n}, i, j \in\{1,2, \ldots, n\}$.

$\boldsymbol{r}=\left[\sum_{j=1}^{n} t_{i j}\right]_{n \times 1}=\left[r_{i}\right]_{n \times 1}=\left(r_{1}, \ldots, r_{i}, \ldots, r_{n}\right)$.

$\boldsymbol{s}=\left[\sum_{i=1}^{n} t_{i j}\right]_{1 \times n}^{\prime}=\left[s_{j}\right]_{n \times 1}=\left(s_{1}, \ldots, s_{j}, \ldots, s_{n}\right)$.

The horizontal $\left(r_{i}+s_{i}\right)$ axis is obtained by getting the sum of $r_{i}$ and $s_{i}$ in order to define the importance of the attribute $i$. Correspondingly, the vertical $\left(r_{i}-s_{i}\right)$ axis is obtained by calculating the difference between $r_{i}$ and $s_{i}$ which will separate the attributes into causal cluster and effect cluster. When $\left(r_{i}-s_{i}\right)$ is positive, then the attribute $i$ is categorized under causal cluster; otherwise, it falls under effect cluster. From this relation, an influential network relations map can be illustrated by plotting $\left(r_{i}+s_{i}\right)$ as independent variable and $\left(r_{i}-s_{i}\right)$ as dependent variable.

Step 7 Find the normalized total-influential matrix $\boldsymbol{T}^{\text {nor }}$.

The matrix $\boldsymbol{T}^{\text {nor }}$ can be computed as $\boldsymbol{T}^{\text {nor }}=\left[t_{i j}^{\text {nor }}\right]_{n \times n}$, where $t_{i j}^{\text {nor }}=t_{i j} / t_{j}$, and $t_{j}=\sum_{i=1}^{n} t_{i j}$. This matrix also represents the column stochastic (weighted) supermatrix and can be further numerically presented as in Eq. (9):

$$
\begin{aligned}
\boldsymbol{T}^{\text {nor }} & =\left[\begin{array}{ccccc}
t_{11} / t_{1} & \ldots & t_{1 j} / t_{j} & \ldots & t_{1 n} / t_{n} \\
\vdots & & \vdots & & \vdots \\
t_{i 1} / t_{1} & \ldots & t_{i j} / t_{j} & \ldots & t_{i n} / t_{n} \\
\vdots & & \vdots & & \vdots \\
t_{n 1} / t_{1} & \ldots & t_{n j} / t_{j} & \ldots & t_{n n} / t_{n}
\end{array}\right] \\
= & {\left[\begin{array}{ccccc}
t_{11}^{\text {nor }} & \ldots & t_{1 j}^{\text {nor }} & \ldots & t_{1 n}^{\text {nor }} \\
\vdots & & \vdots & & \vdots \\
t_{i 1}^{\text {nor }} & \ldots & t_{i j}^{\text {nor }} & \ldots & t_{i n}^{\text {nor }} \\
\vdots & & \vdots & & \vdots \\
t_{n 1}^{\text {nor }} & \ldots & t_{n j}^{\text {nor }} & \ldots & t_{n n}^{\text {nor }}
\end{array}\right] . }
\end{aligned}
$$

Step 8 Obtain the DEMATEL-ANP limiting supermatrix.

The weighted supermatrix (i.e., matrix $\boldsymbol{T}^{\text {nor }}$ ) is raised to a large power $\varphi$ until such matrix components converge and become a long-term stable (limiting) supermatrix to obtain global priority vector. This vector represents the influential weights of each corresponding attribute.

\section{Results}

Using Microsoft Excel@ 2016 spreadsheets, the key results of the hybrid MCDM approach based on fuzzy DEMATEL and ANP are obtained. The corresponding triangular fuzzy number assigned to each linguistic expression used by decision-makers in evaluating the relational impact among attributes is initially aggregated as shown in Table 9 of Appendix using Eq. (1). The results are represented by fuzzy numbers; therefore, a defuzzification method shown in Eq. (2) is used to obtain its corresponding crisp values listed in Table 3. The crisp values in Table 3 also represent the direct-influential matrix obtained by means of Eq. (3). Furthermore, the mutual influence of attributes is also indicated on the same matrix. The direct-influential matrix is normalized using Eq. (4) and is shown in Table 4. This normalized direct-influential matrix is transformed into a total-influential matrix shown in Table 5 using Eq. (5). In reference to this table, the row sums and column sums as in Eqs. (7) and (8) are computed to demonstrate the importance of each attribute. When a positive value of $\left(r_{i}-s_{i}\right)$ is obtained, then the specific attribute is classified as a causal attribute; otherwise, it is considered as an effect attribute. Note that in Table 6 , the attributes $C_{1}$ (cost of using the flight routes), $C_{2}$ (landing/take-off fee), $C_{3}$ (fuel cost), $C_{4}$ (extra crew cost), $C_{5}$ (passenger cost), and $C_{7}$ (safety) have positive values of $\left(r_{i}-s_{i}\right)$. This lists these attributes under causal cluster and further implies that an influence is evident from these attributes toward the others. To visually present the mutual influence among attributes, an influential network relations map is created by plotting the data set of $\left(r_{i}+s_{i}, r_{i}-s_{i}\right)$. This is shown in Fig. 1. For example, it can be seen that $C_{7}$ (safety) has arrows pointing toward the other attributes which signifies that it has an influence on them; on the other hand, there are arrows pointing toward $C_{7}$ (safety) which illustrates that this attribute is affected by some other attributes. In the next step, the total-influential matrix is computed using Eq. (6) and the results are listed in Table 5. This matrix is also known as unweighted supermatrix. Then, Table 7 presents the normalized totalinfluential matrix, which is also termed as the weighted supermatrix, computed using Eq. (9). By raising the weighted supermatrix to a sufficiently large power, a global priority vector is obtained and becomes a long-term stable supermatrix. The global priority vector is defined as the influential weights of each attribute shown in Table 8 following step 8 in the hybrid approach.

From the results of fuzzy DEMATEL method, Table 6 summarizes the particular cluster to which each attribute belongs based on the influences given and received by such attribute. It is remarkable that 6 out of 12 attributes fall under causal cluster namely $C_{1}$ (cost of using the flight 
Table 3 Defuzzified relational impact among attributes representing the direct-influential matrix $\boldsymbol{G}$

\begin{tabular}{lllllllllllll}
\hline Attributes & $C_{1}$ & $C_{2}$ & $C_{3}$ & $C_{4}$ & $C_{5}$ & $C_{6}$ & $C_{7}$ & $C_{8}$ & $C_{9}$ & $C_{10}$ & $C_{11}$ & $C_{12}$ \\
\hline$C_{1}$ & 0.125 & 0.317 & 0.317 & 0.317 & 0.317 & 0.317 & 0.567 & 0.567 & 0.567 & 0.508 & 0.317 & 0.442 \\
$C_{2}$ & 0.442 & 0.125 & 0.317 & 0.317 & 0.317 & 0.317 & 0.442 & 0.508 & 0.567 & 0.442 & 0.692 & 0.317 \\
$C_{3}$ & 0.375 & 0.317 & 0.125 & 0.442 & 0.442 & 0.508 & 0.442 & 0.508 & 0.317 & 0.508 & 0.567 & 0.508 \\
$C_{4}$ & 0.317 & 0.317 & 0.442 & 0.125 & 0.508 & 0.508 & 0.508 & 0.508 & 0.317 & 0.508 & 0.442 & 0.508 \\
$C_{5}$ & 0.317 & 0.317 & 0.442 & 0.508 & 0.125 & 0.508 & 0.508 & 0.508 & 0.442 & 0.508 & 0.508 & 0.508 \\
$C_{6}$ & 0.317 & 0.317 & 0.508 & 0.508 & 0.508 & 0.125 & 0.508 & 0.508 & 0.442 & 0.508 & 0.508 & 0.508 \\
$C_{7}$ & 0.317 & 0.442 & 0.442 & 0.508 & 0.508 & 0.567 & 0.125 & 0.758 & 0.758 & 0.758 & 0.758 & 0.692 \\
$C_{8}$ & 0.317 & 0.508 & 0.508 & 0.508 & 0.508 & 0.567 & 0.508 & 0.125 & 0.508 & 0.317 & 0.508 & 0.508 \\
$C_{9}$ & 0.317 & 0.508 & 0.317 & 0.317 & 0.317 & 0.317 & 0.758 & 0.508 & 0.125 & 0.442 & 0.700 & 0.508 \\
$C_{10}$ & 0.317 & 0.442 & 0.508 & 0.442 & 0.508 & 0.508 & 0.700 & 0.508 & 0.508 & 0.125 & 0.567 & 0.633 \\
$C_{11}$ & 0.317 & 0.442 & 0.567 & 0.442 & 0.508 & 0.508 & 0.508 & 0.508 & 0.567 & 0.700 & 0.317 & 0.700 \\
$C_{12}$ & 0.317 & 0.317 & 0.508 & 0.508 & 0.508 & 0.508 & 0.442 & 0.508 & 0.508 & 0.633 & 0.633 & 0.125 \\
\hline
\end{tabular}

Table 4 Normalized direct-influential matrix $X$

\begin{tabular}{lllllllllllll}
\hline Attributes & $C_{1}$ & $C_{2}$ & $C_{3}$ & $C_{4}$ & $C_{5}$ & $C_{6}$ & $C_{7}$ & $C_{8}$ & $C_{9}$ & $C_{10}$ & $C_{11}$ & $C_{12}$ \\
\hline$C_{1}$ & 0.000 & 0.048 & 0.048 & 0.048 & 0.048 & 0.048 & 0.085 & 0.085 & 0.085 & 0.077 & 0.048 & 0.067 \\
$C_{2}$ & 0.067 & 0.000 & 0.048 & 0.048 & 0.048 & 0.048 & 0.067 & 0.077 & 0.085 & 0.067 & 0.104 & 0.048 \\
$C_{3}$ & 0.057 & 0.048 & 0.000 & 0.067 & 0.067 & 0.077 & 0.067 & 0.077 & 0.048 & 0.077 & 0.085 & 0.077 \\
$C_{4}$ & 0.048 & 0.048 & 0.067 & 0.000 & 0.077 & 0.077 & 0.077 & 0.077 & 0.048 & 0.077 & 0.067 & 0.077 \\
$C_{5}$ & 0.048 & 0.048 & 0.067 & 0.077 & 0.000 & 0.077 & 0.077 & 0.077 & 0.067 & 0.077 & 0.077 & 0.077 \\
$C_{6}$ & 0.048 & 0.048 & 0.077 & 0.077 & 0.077 & 0.000 & 0.077 & 0.077 & 0.067 & 0.077 & 0.077 & 0.077 \\
$C_{7}$ & 0.048 & 0.067 & 0.067 & 0.077 & 0.077 & 0.085 & 0.000 & 0.114 & 0.114 & 0.114 & 0.114 & 0.104 \\
$C_{8}$ & 0.048 & 0.077 & 0.077 & 0.077 & 0.077 & 0.085 & 0.077 & 0.000 & 0.077 & 0.048 & 0.077 & 0.077 \\
$C_{9}$ & 0.048 & 0.077 & 0.048 & 0.048 & 0.048 & 0.048 & 0.114 & 0.077 & 0.000 & 0.067 & 0.106 & 0.077 \\
$C_{10}$ & 0.048 & 0.067 & 0.077 & 0.067 & 0.077 & 0.077 & 0.106 & 0.077 & 0.077 & 0.000 & 0.085 & 0.095 \\
$C_{11}$ & 0.048 & 0.067 & 0.085 & 0.067 & 0.077 & 0.077 & 0.077 & 0.077 & 0.085 & 0.106 & 0.000 & 0.106 \\
$C_{12}$ & 0.048 & 0.048 & 0.077 & 0.077 & 0.077 & 0.077 & 0.067 & 0.077 & 0.077 & 0.095 & 0.095 & 0.000 \\
\hline
\end{tabular}

Table 5 Total-influential matrix $\boldsymbol{T}$ (i.e., unweighted supermatrix)

\begin{tabular}{|c|c|c|c|c|c|c|c|c|c|c|c|c|}
\hline Attributes & $C_{1}$ & $C_{2}$ & $C_{3}$ & $C_{4}$ & $C_{5}$ & $C_{6}$ & $C_{7}$ & $C_{8}$ & $C_{9}$ & $C_{10}$ & $C_{11}$ & $C_{12}$ \\
\hline$C_{1}$ & 0.162 & 0.237 & 0.263 & 0.260 & 0.266 & 0.274 & 0.337 & 0.336 & 0.321 & 0.326 & 0.318 & 0.320 \\
\hline$C_{2}$ & 0.229 & 0.196 & 0.268 & 0.264 & 0.271 & 0.279 & 0.326 & 0.334 & 0.327 & 0.324 & 0.373 & 0.310 \\
\hline$C_{3}$ & 0.228 & 0.250 & 0.235 & 0.294 & 0.301 & 0.318 & 0.338 & 0.347 & 0.305 & 0.347 & 0.370 & 0.349 \\
\hline$C_{4}$ & 0.219 & 0.249 & 0.296 & 0.230 & 0.308 & 0.316 & 0.344 & 0.345 & 0.303 & 0.344 & 0.352 & 0.347 \\
\hline$C_{5}$ & 0.225 & 0.256 & 0.304 & 0.309 & 0.245 & 0.325 & 0.355 & 0.355 & 0.329 & 0.354 & 0.371 & 0.357 \\
\hline$C_{6}$ & 0.227 & 0.259 & 0.316 & 0.312 & 0.319 & 0.256 & 0.358 & 0.358 & 0.332 & 0.357 & 0.375 & 0.360 \\
\hline $\mathrm{C}_{7}$ & 0.272 & 0.330 & 0.368 & 0.371 & 0.380 & 0.398 & 0.360 & 0.461 & 0.441 & 0.460 & 0.483 & 0.456 \\
\hline$C_{8}$ & 0.231 & 0.288 & 0.319 & 0.316 & 0.322 & 0.339 & 0.362 & 0.292 & 0.345 & 0.337 & 0.380 & 0.364 \\
\hline$C_{9}$ & 0.225 & 0.283 & 0.287 & 0.283 & 0.290 & 0.299 & 0.387 & 0.356 & 0.269 & 0.347 & 0.398 & 0.357 \\
\hline$C_{10}$ & 0.245 & 0.296 & 0.339 & 0.326 & 0.342 & 0.352 & 0.410 & 0.386 & 0.368 & 0.315 & 0.413 & 0.404 \\
\hline$C_{11}$ & 0.248 & 0.299 & 0.351 & 0.330 & 0.346 & 0.356 & 0.391 & 0.390 & 0.379 & 0.415 & 0.339 & 0.417 \\
\hline$C_{12}$ & 0.236 & 0.269 & 0.327 & 0.323 & 0.330 & 0.339 & 0.363 & 0.371 & 0.353 & 0.387 & 0.404 & 0.302 \\
\hline
\end{tabular}


Table 6 Sum of influences given and received on and by each attribute

\begin{tabular}{llllrl}
\hline Attributes & $r_{i}$ & $s_{i}$ & $r_{i}+s_{i}$ & $r_{i}-s_{i}$ & Clusters \\
\hline$C_{1}$ & 3.422 & 2.748 & 6.170 & 0.674 & Causal \\
$C_{2}$ & 3.501 & 3.212 & 6.712 & 0.289 & Causal \\
$C_{3}$ & 3.682 & 3.672 & 7.354 & 0.010 & Causal \\
$C_{4}$ & 3.653 & 3.618 & 7.271 & 0.034 & Causal \\
$C_{5}$ & 3.785 & 3.720 & 7.505 & 0.066 & Causal \\
$C_{6}$ & 3.829 & 3.850 & 7.680 & -0.021 & Effect \\
$C_{7}$ & 4.781 & 4.331 & 9.112 & 0.450 & Causal \\
$C_{8}$ & 3.894 & 4.330 & 8.225 & -0.436 & Effect \\
$C_{9}$ & 3.781 & 4.072 & 7.853 & -0.291 & Effect \\
$C_{10}$ & 4.195 & 4.313 & 8.508 & -0.119 & Effect \\
$C_{11}$ & 4.260 & 4.575 & 8.835 & -0.315 & Effect \\
$C_{12}$ & 4.003 & 4.345 & 8.347 & -0.342 & Effect \\
\hline
\end{tabular}

routes), $C_{2}$ (landing/take-off fee), $C_{3}$ (fuel cost), $C_{4}$ (extra crew cost), $C_{5}$ (passenger cost), and $C_{7}$ (safety). This implies that the prominence of these attributes in terms of its relation to other attributes is consistent. While attributes that fall under effect cluster are $C_{6}$ (customer goodwill), $C_{8}$ (equitable treatment of competing airline), $C_{9}$ (utilization of runway and terminal), $C_{10}$ (environmental value), $C_{11}$ (economic value), and $C_{12}$ (social value), these attributes are in one way or another affected by other attributes and thus also carry the possible penalties of not being able to properly adhere due to considerations to attributes that fall under the causal cluster.
The results in Table 7 can be interpreted according to the impact one attribute has on another. Take for example the cell highlighted in bolditalic, it shows that $C_{7}$ (attribute on the leftmost column of the table) has an influence of 0.10 to $C_{5}$. A threshold value is established in order to eliminate minor influences among attributes [29]. This is accomplished by computing for the average value of the elements in the total-influential matrices on all conditions. For this paper, a threshold value of 0.083 is computed. When the relationships between attributes are greater than the threshold value, a significant relationship can be inferred; otherwise, its impact may be irrelevant. As indicated in Table 7, the matrix elements formatted in bold are those that are greater than the set threshold value. It suggests strong relation among attributes. For instance, looking at the row on $C_{7}$ (safety), it can be noted that it is formatted bold at all cells corresponding to the remaining 11 attributes. This implies that safety influences all other attributes in coming up with a decision to mitigate air traffic congestion. In reference to earlier studies that also used MCDM approaches, stakeholders in the commercial aviation industry who strive to sustain competitive advantage believed that the most important attribute to improve and focus on is safety $[11,30]$. In the local context, it also reflects similar results considering that the elicited judgment of decision-makers converges to a relevant impact of safety on other attributes, ranging from cost-related ones to general air transport concerns.

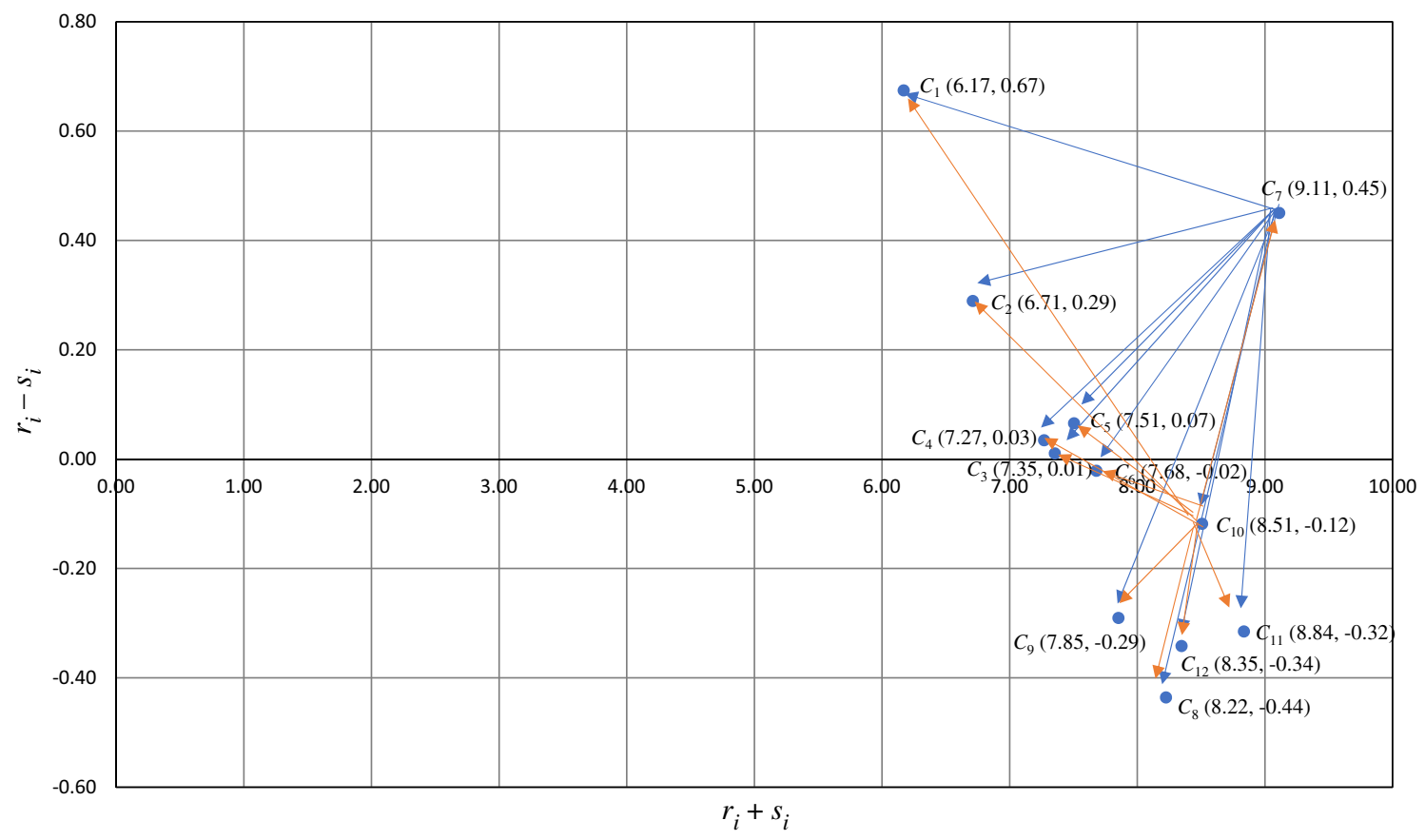

Fig. 1 Influential network relations map 
Table 7 Normalized total-influential matrix $\boldsymbol{T}^{\text {nor }}$ (i.e., weighted supermatrix)

\begin{tabular}{|c|c|c|c|c|c|c|c|c|c|c|c|c|}
\hline Attributes & $C_{1}$ & $C_{2}$ & $C_{3}$ & $C_{4}$ & $C_{5}$ & $C_{6}$ & $C_{7}$ & $C_{8}$ & $C_{9}$ & $C_{10}$ & $C_{11}$ & $C_{12}$ \\
\hline$C_{1}$ & 0.059 & 0.074 & 0.072 & 0.072 & 0.072 & 0.071 & 0.078 & 0.078 & 0.079 & 0.076 & 0.070 & 0.074 \\
\hline$C_{2}$ & 0.083 & 0.061 & 0.073 & 0.073 & 0.073 & 0.072 & 0.075 & 0.077 & 0.080 & 0.075 & 0.082 & 0.071 \\
\hline$C_{3}$ & 0.083 & 0.078 & 0.064 & 0.081 & 0.081 & 0.083 & 0.078 & 0.080 & 0.075 & 0.080 & 0.081 & 0.080 \\
\hline$C_{4}$ & 0.080 & 0.077 & 0.081 & 0.064 & 0.083 & 0.082 & 0.080 & 0.080 & 0.074 & 0.080 & 0.077 & 0.080 \\
\hline$C_{5}$ & 0.082 & 0.080 & 0.083 & 0.085 & 0.066 & 0.084 & 0.082 & 0.082 & 0.081 & 0.082 & 0.081 & 0.082 \\
\hline$C_{6}$ & 0.083 & 0.081 & 0.086 & 0.086 & 0.086 & 0.067 & 0.083 & 0.083 & 0.081 & 0.083 & 0.082 & 0.083 \\
\hline $\mathrm{C}_{7}$ & 0.099 & 0.103 & 0.100 & 0.103 & 0.102 & 0.103 & 0.083 & 0.107 & 0.108 & 0.107 & 0.106 & 0.105 \\
\hline$C_{8}$ & 0.084 & 0.090 & 0.087 & 0.087 & 0.087 & 0.088 & 0.084 & 0.067 & 0.085 & 0.078 & 0.083 & 0.084 \\
\hline$C_{9}$ & 0.082 & 0.088 & 0.078 & 0.078 & 0.078 & 0.078 & 0.089 & 0.082 & 0.066 & 0.080 & 0.087 & 0.082 \\
\hline$C_{10}$ & 0.089 & 0.092 & 0.092 & 0.090 & 0.092 & 0.091 & 0.095 & 0.089 & 0.090 & 0.073 & 0.090 & 0.093 \\
\hline$C_{11}$ & 0.090 & 0.093 & 0.095 & 0.091 & 0.093 & 0.092 & 0.090 & 0.090 & 0.093 & 0.096 & 0.074 & 0.096 \\
\hline$C_{12}$ & 0.086 & 0.084 & 0.089 & 0.089 & 0.089 & 0.088 & 0.084 & 0.086 & 0.087 & 0.090 & 0.088 & 0.070 \\
\hline
\end{tabular}

The data values in bold are equal to or greater than threshold value 0.083 , which signify a strong degree of relationship between attributes

Table 8 Influential weights of each attribute generated from the long-term stable supermatrix

\begin{tabular}{llr}
\hline Attributes & Influential weights & Rank \\
\hline$C_{1}$ & 0.073 & 12 \\
$C_{2}$ & 0.075 & 11 \\
$C_{3}$ & 0.079 & 9 \\
$C_{4}$ & 0.078 & 10 \\
$C_{5}$ & 0.081 & 8 \\
$C_{6}$ & 0.082 & 6 \\
$C_{7}$ & 0.102 & 1 \\
$C_{8}$ & 0.083 & 5 \\
$C_{9}$ & 0.081 & 7 \\
$C_{10}$ & 0.090 & 3 \\
$C_{11}$ & 0.091 & 2 \\
$C_{12}$ & 0.086 & 4 \\
\hline
\end{tabular}

\section{Discussion and insights}

This section further lay actual conditions on how each attribute influences other attributes and how it is likewise influenced by another. The results obtained from Tables 6 and 7 are used as a reference for discussion.

\subsection{Attributes under the causal cluster}

\subsection{1 $C_{1}$ (cost of using the flight routes)}

It is important to recognize that each flight route has unique charges when requested to be used during contingencies. While ATS regulates orders, the airport management is there to implement such regulations and at the same time provide service to their clients, in the being of the airline industry, by means of establishing physical structures such as terminals, runways, and the airport as a whole. In the same way, the airline industry is further required to operate under the rule of the general air transportation guidelines. This provides grounds why airline industry is charged accordingly upon the non-compliance of the issued flight route for a specific flight. As regards the impact $C_{1}$ (cost of using the flight routes) has on other attributes, no significant relations are evident based on Table 7. Although the results in Table 6 classified this attribute under the causal cluster (i.e., affecting other attributes), its effect on other attributes can be safely considered minor according to the threshold value obtained.

\subsection{2 $C_{2}$ (landing/take-off fee)}

Looking at $C_{2}$ (landing/take-off fee) in Table 7, row values are not greater than the threshold value which indicates that this attribute does not necessarily give out an impact of worthy significance on other attributes. This result does coincide with the fact that landing/take-off fee is determined by some other factors (e.g., the weight of aircraft, number of seats, time of day, aircraft home airport, and operator class) and not by the remaining 11 attributes specified in this paper. Though landing/take-off fees are significantly affected by $C_{7}$ (safety), $C_{8}$ (equitable treatment of competing airline), $C_{9}$ (utilization of runway and terminal), $C_{10}$ (environmental value), $C_{11}$ (economic value), according to $C_{2}$ column of Table 7 , it can also be observed that among these attributes which affect $C_{2}$ (landing/take-off fee), aside from $C_{7}$ (safety), it is $C_{9}$ (utilization of runway and terminal) that has highest influential relations value, along with $C_{10}$ (environmental value) and $C_{11}$ (economic value). In another circumstance, $C_{2}$ (landing/take-off fee) shows a significant influence on $C_{11}$ (economic value). It can be justified by the fact that 
landing/take-off fees vary between airports-congested ones usually charge higher landing/take-off fees because of the law of supply and demand, while less congested airports may charge less because demand is not at all as high [31].

\subsection{3 $C_{3}$ (fuel cost)}

According to the normalized total-influential matrix earlier presented in Table 7, generally, $C_{3}$ 's (fuel cost) classification as part of the causal cluster is not depicted statistically in this table. However, one decision-maker stressed that more fuel costs incurred translate to an increase in fuel consumption, thereby, not only increasing fuel burn but also aggravating noise pollution-both essential to preserving a region's environmental value as represented by $C_{10}$ (environmental value). A prior paper conducted by Babic et al. [22] verified that, indeed, there are issues related to environmental impact when fuel consumption is increased significantly, let alone when aircraft fly in less efficient trajectories.

\subsection{4 $C_{4}$ (extra crew cost)}

For $C_{4}$ (extra crew cost), this attribute falls under the causal cluster as shown in Table 6 . In reference to Table 7, $C_{4}$ does not contribute a significant impact to other attributes as its row values are not greater than the threshold value 0.083. In contrast, results from Table 6 show that since $C_{4}$ (extra crew cost) fall under the causal cluster, a significant impact on other attributes should be apparent. At a deeper level, extra crew costs can be due to poor crew scheduling resulting in delays and even cancellation of flights [32]. Additionally, airline industry also reports that when crews and aircraft needed for subsequent flights are unavailable, other factors such as fuel consumption, passenger costs, customer goodwill, utilization of runway and terminal, environmental value, and social value can be potentially affected in such a way that when delays occur, a corresponding penalty shall be charged to the concerned stakeholder.

\subsection{5 $C_{5}$ (passenger cost)}

Table 7 displays that $C_{5}$ (passenger cost) has a significant impact on $C_{6}$ (customer goodwill), and less to insignificant impact on the remaining attributes. Based on this result, it is not surprising to recognize that the attractiveness of air travel (i.e., attributable to customer goodwill) is characterized by well-performing flight operations, equating to lesser passenger-related costs such as compensation plans due to delays, cancellations, denied boarding, and lost luggage, to name just a few. Additionally, $C_{5}$ (passenger cost) receives significant impact from six attributes, namely $C_{6}$ (customer goodwill), $C_{7}$ (safety), $C_{8}$ (equitable treatment of competing airline), $C_{10}$ (environmental value), $C_{11}$ (economic value), and $C_{12}$ (social value). These six attributes consequently affect passenger cost in a negative way when these are not managed efficiently.

\subsection{6 $C_{7}$ (safety)}

For $C_{7}$ (safety), it holds the highest $r$ (sum) value as shown in Table 6, which signifies that this attribute is given most importance when a decision should be made in the event of air traffic congestion. This is supported by the fact that $C_{7}$ (safety) is perceived by decision-makers to highly influence other attributes from the results in Table 7. It is further emphasized by decision-makers that other attributes may potentially be minimized accordingly when safety is kept to maximum. One concrete example is as follows: according to decision-makers, excess fuel costs associated to delays are less likely to be incurred by the airlines management when aircraft are kept on the ground instead of holding them in the air (i.e., by means of airborne holding at arrival holding stacks, rerouting, or speed controlling) which, in theory according to Ball et al. [20] and Andreatta et al. [33], and validated in reality by decisionmakers, is less safe to implement compared to ground holding. Another example compares the relevance between safety and both economic and social value. When flights are delivered safely in the assumption that air traffic congestion is likewise minimized, the economic output of the air transport sector will generally increase resulting from an increased demand for air travel. This statement from decision-makers coincides with prior definitions of Vanderschuren et al. [13] that as air travel demand increases, the economy and social value grows proportionally. The same can also be inferred when other intangible attributes are tackled such as customer goodwill, equitable treatment of competing airline, utilization of runway and terminal, and environmental value.

On the other hand, the influence of $C_{7}$ (safety) on $C_{9}$ (utilization of runway and terminal) can be brought about by the fact that while the aim of mitigating air traffic congestion is achieved through safe operation of flights, the runways and terminals are also utilized. Safe operation of flights means that all necessary measures are taken, whether that would result in holding as many flights on the ground or creating an orderly pattern of flight schedules. Furthermore, it is imperative to note that the definition of a utilized runway is given, according to decision-maker designated in overseeing the utilization of airport resources, as a metric of housing the most number of aircraft at any given time. It is also being emphasized that the term 'runway' associated to attribute $C_{9}$ (utilization of runway 
and terminal) includes the apron where gates are found and where ground handling activities are carried out.

\subsection{Attributes under effect cluster}

\subsection{1 $C_{6}$ (customer goodwill)}

Based on Table 7, this attribute provides a significant impact on $C_{3}$ (fuel cost), $C_{4}$ (extra crew cost), and $C_{5}$ (passenger cost) and are likewise affected by $C_{5}$ (passenger cost), $C_{7}$ (safety), $C_{8}$ (equitable treatment of competing airline), $C_{10}$ (environmental value), $C_{11}$ (economic value), and $C_{12}$ (social value). Recall from earlier discussions that the impact of $C_{6}$ (customer goodwill) on $C_{5}$ (passenger cost) can be found in enticing more air passengers and having them satisfied about their air travel experience. Again, there will be no corresponding passenger costs associated with a satisfied air passenger since disturbances like long, unacceptable delays, on-the-day cancellations, and missing luggage are avoided. Note in Table 6 that the $\left(r_{i}-s_{i}\right)$ value of this attribute is very small in figure, and is so close to being classified under causal cluster. It can be manifested in the following scenarios. Recall that customer goodwill is an intangible asset of any airline industry and is a result of an efficient flight performance. When air passengers are fully satisfied with the service quality of the airlines, it already denotes that no excess fuel costs and extra crew costs are incurred accordingly, because no delays are further experienced. Simply, lesser to no delay means lesser excess fuel and extra crew costs to airlines and meanwhile means satisfaction to air passengers.

\subsection{2 $C_{8}$ (equitable treatment of competing airline)}

As for $C_{8}$ (equitable treatment of competing airline), one concrete example of its classification as an effect attribute can be observed through its relation to $C_{1}$ (cost of using the flight routes). Strictly, flight routes along an airspace have various configurations and parameters described for each. In the event of air traffic congestion where an alternate flight route is taken, a penalization of the deviation of the total trip length from that scheduled and the deviation of the actual travel time from that scheduled for each flight is charged to the airlines concerned [34]. The same penalization is charged to all airlines regardless of its capital structure and market position, thus demonstrating an equitable treatment of among airlines. While a tangible penalization is quantified for deviation of total trip length and actual travel time, the act of using an alternate flight route likewise affects $C_{10}$ (environmental value) in a way that emissions of harmful chemicals are further intensified as a result of such action.

\subsection{3 $C_{9}$ (utilization of runway and terminal)}

Based on Table 7, $C_{9}$ (utilization of runway and terminal) receives the least to no influence from attributes that fall under tangible and intangible costs which are charged directly to the airline industry such as $C_{2}$ (landing/takeoff fee), $C_{3}$ (fuel cost), $C_{4}$ (extra crew cost), and $C_{6}$ (customer goodwill) - this is due to the fact that these attributes attributable to the airline industry do not necessarily pose any impact on the utilization of runway and terminal. That is, an increase of such related costs can neither contribute to the utilization of an airport's runway. The same inference can also be made for another attribute as in $C_{8}$ (equitable treatment of competing airline). On the other hand, based on the total-influential matrix in Table 7, there is a significant influence given by these four attributes $\left(C_{7}, C_{10}, C_{11}\right.$, and $\left.C_{12}\right)$ on $C_{9}$ (utilization of runway and terminal). This is significantly higher than the average effect from the rest of the attributes $\left(C_{1}, C_{2}\right.$, $C_{3}, C_{4}, C_{5}, C_{6}, C_{8}$, and $C_{9}$ ), which is only at 0.08 influence.

\subsection{4 $C_{10}$ (environmental value)}

According to Table 7, $C_{10}$ (environmental value) is significantly affected by $C_{7}$ (safety), $C_{11}$ (economic value), and $C_{12}$ (social value). As to how environmental value is affected by such attributes, it can be described by looking at $C_{7}$ (safety) first. While there are ATFM actions that are perceived safer to implement during air traffic congestion, its effects can be noted from the emissions made by the aircraft upon execution of such actions directly degrading the environment. Also, in the efforts of progressing air transportation system in both economic and social aspects, a share of environmental compromise may arise particularly when strict modification is done (e.g., building a new runway in a completely non-commercial area).

\subsection{5 $C_{11}$ (economic value)}

As for $C_{11}$ (economic value), it has a total impact of 0.09 on $C_{9}$ (utilization of runway and terminal) and thus signifies a notable influence. For example, as an economy or a region develop infrastructures for air transportation in response to a growing demand for air travel, runways and terminals are dominantly utilized as a result of it.

\subsection{6 $C_{12}$ (social value)}

This attribute receives a significant effect from $C_{7}$ (safety), $C_{10}$ (environmental value), and $C_{11}$ (economic value) according to Table 7 . Although not statistically evident in the table, $C_{12}$ (social value) also affects $C_{5}$ (passenger 
cost). One common example is as follows: the social value of a region has more chances of actually progressing when more air passengers are satisfied with their air travel experience. A satisfying air travel experience is defined to be free from disturbances such as long, unacceptable delays, on-the-day cancellations, and missing luggage. Otherwise, the airline industry is required to properly compensate for the air passengers.

\section{Policy implications}

According to the influential weights of each attribute and its corresponding rank shown in Table 8 , it shows that safety is believed to be the topmost consideration in mitigating air traffic congestion. Following next to safety are attributes that are accountable to the general welfare of the air transportation system such as equitable treatment of competing airline, utilization of runway and terminal, environmental value, economic value, and social value. This suggests that these attributes are, in general, also given due priorities by the pooled decision-makers, despite the fact that they are independent entities with different objectives. On the other hand, attributes that represent both tangible and intangible congestion costs associated with the airline industry, such as the cost of using the flight routes, landing/take-off fee, fuel cost, extra crew cost, passenger cost, and customer goodwill, fall under the last few ranks garnering lower influential weights. This can be caused by the fact that among the decision-makers involved, there is only one entity that is obliged to pay for congestion costs. Although, in actual practice, the three stakeholders (i.e., airline industry, airport management, and ATS providers) are interrelated in terms of the promulgation of regulations and other necessary protocols, it is the airlines that face the direct consequences of congestion in the form of paying for the cost of using the flight routes, landing/take-off fee, fuel cost, extra crew cost, passenger cost, and maintaining, if not improving customer goodwill.

In reference to the key results obtained from the fuzzy MCDM approach (i.e., critical attributes to be considered in the decision support system), several policies can be formulated by stakeholders and policy-makers to address air traffic congestion. These policies can serve as points of interest to one or more stakeholders for a specific congestion condition.

\subsection{Short-term air transport policies}

All stakeholders recognize that failure to maintain safe operation of flights will correspondingly affect other attributes significantly. This result is expectedly in parallel with the objective of ATS, in particular, which seeks to provide not only a safe but also the orderly and expeditious flow of air traffic. While airlines management and airport management are entities concerned with its very own wide array of auxiliary goals which may include cost-related and reputation-wise considerations, it is imperative to recognize that these entities likewise strive most for the safe conduct of flights. Therefore, possible policies that promote aviation safety must be strictly regulated by ATS providers and obediently observed by the airport management and airlines industry. These policies may include the development of the currently imposed Memorandum Circular No. 15-12 which mandates airlines to hold flights on the ground when there is anticipated destination airport congestion or airspace congestion. Under this memorandum, when an aircraft is unable to depart at its assigned estimated departure clearance time, airlines are required to submit a change/delay message indicating a new estimated off-blocks time (EOBT). The nominal probability of submitting a new EOBT is, however, charged directly as a penalty of the aircraft in the form of a departure delay caused by excess ground holding. In the interest of promptness and schedule reliability of airlines and wise utilization of airport facilities, stakeholders must formulate policies that limit the ground holding of aircraft to a specific duration so as not to disturb the dynamics of flight schedules set during the day.

In conditions of air traffic congestion, when holding flights on the ground may not be a feasible option, other ATFM actions such as airborne holding, rerouting, and speed control can be implemented as necessary. Stakeholders must, nevertheless, uphold safe operation of flights especially that aircraft involved are already en-route. Therefore, utmost safety must be observed by formulating policies that will mandate aircraft waiting for landing clearance to be held airborne for the shortest time possible.

\subsection{Long-term air transport policies}

The previously mentioned memorandum takes effect only when tactical planning (i.e., actions are applied on the day of operation) is framed. In the long-run, stakeholders must be able to develop strategies that will diligently address air traffic congestion with respect to dominant attributes such as safety, general air transportation concerns, and congestion costs. Note that the issue of air traffic congestion roots from insufficient resource capacities; therefore, the emphasis of long-term transport policies must be based on expanding such capacities in order to cater for the growing demand for air travel. This includes construction of additional runway, slots, and terminal facilities along with the engagement of technological advances for better air traffic coordination. While these strategies are widely believed to increase capacity, considerable attention should be paid not 
only to huge investments needed to fully realize such strategies but also to political interests that stakeholders may independently have. Another strategy to address air traffic congestion may also include reducing air travel demand itself, which might entail challenges since it can hamper the further progress of the country's economic, tourism, and social rights.

\section{Conclusion}

Air traffic congestion has become a widely tackled issue in the current literature which is addressed using various methodologies from algorithms to optimization models and considering diverse, case-specific air traffic scenarios. However, there is limited research that extracts the inherent relations among multiple attributes involved in the decision-making problem in the air transportation system as well as reflects on a generalized case of air traffic congestion which captures the possibility of both airport and airspace congestion. Therefore, this paper contributes to the body of knowledge by identifying critical attributes during air traffic congestion using hybrid MCDM methods based on the concepts of fuzzy DEMATEL and ANP. Out of all the 12 attributes considered in this paper, the attribute on safety consistently garnered the highest influential weight. Following this attribute are those that are generally concerned with the betterment of the overall air transportation sector and congestion costs.

Based on the findings presented, the following conclusions can be drawn. First, the decision-makers, although by nature are independent entities motivated to carry out strategies in line with their individual auxiliary goals, converge to the idea that safety in air transportation should be upheld and maintained at all times. Second, attributes concerned with the general welfare of air transportationgenerate high influential weights next to safety. Apparently, decision-makers recognize that these attributes are likewise instrumental not only in the smooth, orderly, and efficient conduct of flights but also in the long-term effects of the overall air transportation system. Lastly, attributes that are directly attributable to the airline industry garner lesser influential weights among others. The results do make sense considering that among the stakeholders in the commercial aviation industry involved in this paper as decision-makers, only one of them (i.e., airlines industry) is obliged to pay for any penalty incurred thereof. The other decision-makers function to regulate orders and correspondingly ensure that these are properly implemented.

A number of air transport policies are proposed to stakeholders in order to address air traffic congestion in accordance to both time horizon of implementation and key results obtained in this paper. For a short-term application, a respective, suitable ATFM action is deemed necessary to be implemented while taking into consideration dominant attributes such as the safe operation of flights. As for longterm application, policies involving expansion of resource capacities are suggested to be formulated to permanently address congestion. While these policies can generally address air traffic congestion based on the priorities of attributes extracted from this paper, it is a necessity for stakeholders and policy-makers to be as receptive as possible despite the prevalence of politics and occasional conflict of their interests.

As an extension to this study, details can be specified when the information of air traffic congestion is known and which resource is congested. This is an important topic to be tackled since priorities given to an attribute for a particular condition may change depending on the occurrence of such congestion.

Acknowledgements The authors wish to thank the following entities for their collective support to this scientific paper: to the key experts in Ninoy Aquino International, Civil Aviation Authority of the Philippines in Mactan, Cebu and Pasay City, Manila, for their provision of data; to the Engineering Research and Development for Technology (ERDT) of the Philippine Department of Science and Technology (DOST) for the financial support provided through the full graduate scholarship grant of the first author; and to the University of San Carlos, Cebu Philippines for providing the resources used. Finally, we are also grateful to the Editor-in-Chief of this journal, Prof. Yong Zhao, and to the three anonymous reviewers who provided valuable constructive comments and suggestions in improving the readability and quality of this paper.

Open Access This article is distributed under the terms of the Creative Commons Attribution 4.0 International License (http:// creativecommons.org/licenses/by/4.0/), which permits unrestricted use, distribution, and reproduction in any medium, provided you give appropriate credit to the original author(s) and the source, provide a link to the Creative Commons license, and indicate if changes were made. 


\section{Appendix}

See Table 9.

Table 9 Aggregate relational impact among attributes in triangular fuzzy numbers representing the direct-influential matrix $\boldsymbol{G}$

\begin{tabular}{|c|c|c|c|c|c|c|}
\hline Attributes & $C_{1}$ & $C_{2}$ & $C_{3}$ & $C_{4}$ & $C_{5}$ & $C_{6}$ \\
\hline$C_{1}$ & $(0.00,0.10,0.30)$ & $(0.17,0.30,0.50)$ & $(0.17,0.30,0.50)$ & $(0.17,0.30,0.50)$ & $(0.17,0.30,0.50)$ & $(0.17,0.30,0.50)$ \\
\hline$C_{2}$ & $(0.27,0.43,0.63)$ & $(0.00,0.10,0.30)$ & $(0.17,0.30,0.50)$ & $(0.17,0.30,0.50)$ & $(0.17,0.30,0.50)$ & $(0.17,0.30,0.50)$ \\
\hline$C_{3}$ & $(0.20,0.37,0.57)$ & $(0.17,0.30,0.50)$ & $(0.00,0.10,0.30)$ & $(0.27,0.43,0.63)$ & $(0.27,0.43,0.63)$ & $(0.33,0.50,0.70)$ \\
\hline$C_{4}$ & $(0.17,0.30,0.50)$ & $(0.17,0.30,0.50)$ & $(0.27,0.43,0.63)$ & $(0.00,0.10,0.30)$ & $(0.33,0.50,0.70)$ & $(0.33,0.50,0.70)$ \\
\hline$C_{5}$ & $(0.17,0.30,0.50)$ & $(0.17,0.30,0.50)$ & $(0.27,0.43,0.63)$ & $(0.33,0.50,0.70)$ & $(0.00,0.10,0.30)$ & $(0.33,0.50,0.70)$ \\
\hline$C_{6}$ & $(0.17,0.30,0.50)$ & $(0.17,0.30,0.50)$ & $(0.33,0.50,0.70)$ & $(0.33,0.50,0.70)$ & $(0.33,0.50,0.70)$ & $(0.00,0.10,0.30)$ \\
\hline $\mathrm{C}_{7}$ & $(0.17,0.30,0.50)$ & $(0.27,0.43,0.63)$ & $(0.27,0.43,0.63)$ & $(0.33,0.50,0.70)$ & $(0.33,0.50,0.70)$ & $(0.40,0.57,0.73)$ \\
\hline$C_{8}$ & $(0.17,0.30,0.50)$ & $(0.33,0.50,0.70)$ & $(0.33,0.50,0.70)$ & $(0.33,0.50,0.70)$ & $(0.33,0.50,0.70)$ & $(0.40,0.57,0.73)$ \\
\hline$C_{9}$ & $(0.17,0.30,0.50)$ & $(0.33,0.50,0.70)$ & $(0.17,0.30,0.50)$ & $(0.17,0.30,0.50)$ & $(0.17,0.30,0.50)$ & $(0.17,0.30,0.50)$ \\
\hline$C_{10}$ & $(0.17,0.30,0.50)$ & $(0.27,0.43,0.63)$ & $(0.33,0.50,0.70)$ & $(0.27,0.43,0.63)$ & $(0.33,0.50,0.70)$ & $(0.33,0.50,0.70)$ \\
\hline$C_{11}$ & $(0.17,0.30,0.50)$ & $(0.27,0.43,0.63)$ & $(0.40,0.57,0.73)$ & $(0.27,0.43,0.63)$ & $(0.33,0.50,0.70)$ & $(0.33,0.50,0.70)$ \\
\hline$C_{12}$ & $(0.17,0.30,0.50)$ & $(0.17,0.30,0.50)$ & $(0.33,0.50,0.70)$ & $(0.33,0.50,0.70)$ & $(0.33,0.50,0.70)$ & $(0.33,0.50,0.70)$ \\
\hline Attributes & $C_{7}$ & $C_{8}$ & $C_{9}$ & $C_{10}$ & $C_{11}$ & $C_{12}$ \\
\hline$C_{1}$ & $(0.40,0.57,0.73)$ & $(0.40,0.57,0.73)$ & $(0.40,0.57,0.73)$ & $(0.40,0.57,0.73)$ & $(0.40,0.57,0.73)$ & $(0.40,0.57,0.73)$ \\
\hline$C_{2}$ & $(0.27,0.43,0.63)$ & $(0.33,0.50,0.70)$ & $(0.27,0.43,0.63)$ & $(0.33,0.50,0.70)$ & $(0.27,0.43,0.63)$ & $(0.33,0.50,0.70)$ \\
\hline$C_{3}$ & $(0.27,0.43,0.63)$ & $(0.33,0.50,0.70)$ & $(0.27,0.43,0.63)$ & $(0.33,0.50,0.70)$ & $(0.27,0.43,0.63)$ & $(0.33,0.50,0.70)$ \\
\hline$C_{4}$ & $(0.33,0.50,0.70)$ & $(0.33,0.50,0.70)$ & $(0.33,0.50,0.70)$ & $(0.33,0.50,0.70)$ & $(0.33,0.50,0.70)$ & $(0.33,0.50,0.70)$ \\
\hline$C_{5}$ & $(0.33,0.50,0.70)$ & $(0.33,0.50,0.70)$ & $(0.33,0.50,0.70)$ & $(0.33,0.50,0.70)$ & $(0.33,0.50,0.70)$ & $(0.33,0.50,0.70)$ \\
\hline$C_{6}$ & $(0.33,0.50,0.70)$ & $(0.33,0.50,0.70)$ & $(0.33,0.50,0.70)$ & $(0.33,0.50,0.70)$ & $(0.33,0.50,0.70)$ & $(0.33,0.50,0.70)$ \\
\hline $\mathrm{C}_{7}$ & $(0.00,0.10,0.30)$ & $(0.57,0.77,0.93)$ & $(0.00,0.10,0.30)$ & $(0.57,0.77,0.93)$ & $(0.00,0.10,0.30)$ & $(0.57,0.77,0.93)$ \\
\hline$C_{8}$ & $(0.33,0.50,0.70)$ & $(0.00,0.10,0.30)$ & $(0.33,0.50,0.70)$ & $(0.00,0.10,0.30)$ & $(0.33,0.50,0.70)$ & $(0.00,0.10,0.30)$ \\
\hline$C_{9}$ & $(0.57,0.77,0.93)$ & $(0.33,0.50,0.70)$ & $(0.57,0.77,0.93)$ & $(0.33,0.50,0.70)$ & $(0.57,0.77,0.93)$ & $(0.33,0.50,0.70)$ \\
\hline$C_{10}$ & $(0.50,0.70,0.90)$ & $(0.33,0.50,0.70)$ & $(0.50,0.70,0.90)$ & $(0.33,0.50,0.70)$ & $(0.50,0.70,0.90)$ & $(0.33,0.50,0.70)$ \\
\hline$C_{11}$ & $(0.33,0.50,0.70)$ & $(0.33,0.50,0.70)$ & $(0.33,0.50,0.70)$ & $(0.33,0.50,0.70)$ & $(0.33,0.50,0.70)$ & $(0.33,0.50,0.70)$ \\
\hline$C_{12}$ & $(0.27,0.43,0.63)$ & $(0.33,0.50,0.70)$ & $(0.27,0.43,0.63)$ & $(0.33,0.50,0.70)$ & $(0.27,0.43,0.63)$ & $(0.33,0.50,0.70)$ \\
\hline
\end{tabular}

\section{References}

1. Hongjun X, Junga $T$ (2012) Optimizing arrival flight delay scheduling based on simulated annealing algorithm. J Phys Procedia 33:348-353

2. ICAO (2006) Safety management manual (Doc 9859 AN/474). International Civil Aviation Organization (ICAO), Montreal

3. Chi H, Gao M, Hu Y, Xu B (2012) Models responding to largearea flight delays in aviation production engineering. Syst Eng Procedia 5:68-73

4. Cavca A, Ozgur M (2014) 0-1 integer programming model for procedural separation of aircraft by ground holding in ATFM. Aerosp Sci Technol 33:1-8

5. Ball MO, Glover CN (2013) Stochastic optimization models for ground delay program planning with equity-efficiency tradeoffs. Transp Res Part C 33:196-202

6. Bard JF, Mohan DN (2008) Reallocating arrival slots during a ground delay program. Transp Res Part B 42:113-134
7. Sölveling G (2011) Scheduling of runway operations for reduced environmental impact. Transp Res Part D 16(2):110-120

8. Barnhart C, Fearing D, Odoni A, Vaze V (2012) Demand and capacity management in air transportation. EURO $\mathrm{J}$ Transp Logist 1(1-2):135-155

9. Janic M (2015) A multi-criteria evaluation of solutions and alternatives for matching capacity to demand in an airport system: the case of London. Transp Plann Technol 38(7):709-737

10. Merkert R, Assaf G (2015) Using DEA models to jointly estimate service quality perception and profitability-evidence from international airports. Transp Res Part A 75:42-50

11. Kuo MS (2011) A novel interval-valued fuzzy MCDM method for improving airlines' service quality in Chinese cross-strait airlines. Transp Res Part E 47:1177-1193

12. Kuo M, Liang G (2011) Combining VIKOR with GRA techniques to evaluate service quality of airports under fuzzy environment. Expert Syst Appl 38(3):1304-1312 
13. Vanderschuren M, Zietsman D (2014) Analytic hierarchy process assessment for potential multi-airport systems: the case of Cape Town. J Air Transp Manag 36:41-49

14. Pacheco RR, Fernandes E (2003) Managerial efficiency of Brazilian airports. Transp Res Part A 37:667-680

15. Bongo MF, Ocampo LA (2017) A hybrid fuzzy MCDM approach for mitigating airport congestion: a case in Ninoy Aquino International Airport. J Air Transp Manag 63:1-16

16. Ivanov N, Netjasov F, Jovanović R, Starita S, Strauss A (2017) Air traffic flow management slot allocation to minimize propagated delay and improve airport slot adherence. Transp Res Part A 95:183-197

17. Chen C (2000) Extensions of the TOPSIS for group decisionmaking under fuzzy environment. Fuzzy Sets Syst 114:1-9

18. Saaty TL (1996) Decision making with dependence and feedback: the analytic network process. RWS Publications Publishers, Pittsburgh

19. Ashley K, Savage I (2010) Pricing congestion for arriving flights at Chicago O'Hare Airport. J Air Transp Manag 16:36-41

20. Ball M, Hansen M, Yoon Y (2011) Optimal route decision with a geometric ground-airborne hybrid model under weather uncertainty. Procedia Soc Behav Sci 17:551-571

21. Alves DP, Crespo AM, Dib MV, Weigang L (2010) Intelligent computing methods in air traffic flow management. Transp Res Part C 18:781-793

22. Babić O, Simić TK (2014) Airport traffic complexity and environment efficiency metrics for evaluation of ATM measures. J Air Transp Manag 42:260-271

23. Fasone V, Giuffrè T, Maggiore $P$ (2012) Multi-airport system as a way of sustainability for airport development: evidence from an Italian case paper. Procedia Soc Behav Sci 53:96-105
24. Morrison SA, Winston C (2008) The effect of FAA expenditures on air travel delays. J Urban Econ 63:669-678

25. Wang M, Chang TC (1995) Tool steel materials selection under fuzzy environment. Fuzzy Sets Syst 72:263-270

26. Tseng M-L (2011) Using a hybrid MCDM model to evaluate firm environmental knowledge management in uncertainty. Appl Soft Comput 11:1340-1352

27. Lin L, Lee H-M (2010) Fuzzy assessment for sampling survey defuzzification by signed distance method. Expert Syst Appl 37:7852-7857

28. TzengGwo-Hshiung W-YC-L (2013) A new hybrid MCDM model combining DANP with VIKOR to improve e-store business. Knowl Based Syst 37:48-61

29. Yang YP, Shieh HM, Leu JD, Tzeng GH (2008) A novel hybrid MCDM model combined with DEMATEL and ANP with applications. Int J Oper Res 5(3):160-168

30. Chang T-Y, Tsaura S-H, Yen C-H (2002) The evaluation of airline service quality by fuzzy MCDM. Tour Manag 23:107-115

31. Wei W (2006) Impact of landing fees on airlines' choice of aircraft size and service frequency in duopoly markets. J Air Transp Manag 12:288-292

32. Zhang D, Yu C, Desai J, Lau H (2016) A math-heuristic algorithm for the integrated air service recovery. Transp Res Part B Methodol 84:211-236

33. Andreatta G, Dell'Olmo P, Lulli G (2014) An aggregate stochastic programming model for air traffic flow management. Eur J Oper Res 215:697-704

34. Agustín A, Alonso-Ayuso A, Escudero LF, Pizarro C (2012) On air traffic flow management with rerouting. Part I: deterministic case. Eur J Oper Res 219(1):156-166 